\title{
Advocacy, public service, and outreach: Why scientists must step up
}

\author{
By Boris Dyatkin
}

$\mathrm{B}_{\mathrm{I}}^{\mathrm{o}}$ orn in Russia to a family of scientists, watched my family make the difficult choice to move to the United States as research and industry opportunities disappeared. While celebrating the successes of scientific achievement in Russia, I witnessed the devastating impact of poor science policy. In the United States, I found an entirely different approach to scientific inquiry, one that has offered tremendous growth but that should never be taken for granted. I encountered the true ramifications of this situation face-to-face the moment that I entered graduate school in 2011. At the time, fiscal austerity became a prevalent governing philosophy, and its implications reverberated through the research institutions around me. However, as I encountered growing uncertainty about the future of scientific progress in this country, I found more opportunities to advocate on behalf of the field that I love. I arrived at the realization that these efforts have real and lasting consequences and are an absolutely essential part of being a scientist in our society.

As George Bernard Shaw said, "The single biggest problem in communication is the illusion that it has taken place." I became unsatisfied with the level of conversation about the scope of scientific policy and the numerous layers of society that it impacts. The media, and much of the discussion in Washington, DC, focused on a few trendy topics and ignored a critical majority of important issues. I did not see how such a onesided and narrow conversation could yield a progressive path forward. I took an opportunity to upgrade the discussion and participated in several Congressional Visitation Days. I, along with a group of fellow student scientists, traveled to
Capitol Hill and met with US Senators, Representatives, and their staffers to discuss the critical aspects of science policy.

In defiance of my expectations and preconceived notions, everyone in Washington warmly received us and strongly considered our issues. A staffer later admitted to me that groups like ours are some of their favorite visiting constituencies. Beyond our efforts, multiple professional societies carry out these visits throughout the year. They stress different aspects of the same grand message: a robust science policy creates high-paying jobs, good health care, clean air and water, and a safe and prosperous country. These advocacy efforts, both in Washington and during town hall meetings across the country, are essential. As our government contemplates a broad array of issues and budget decisions, other groups speak with constituents and schedule meetings with politicians. They work tirelessly to get their interests on the table in the places that matter. If we do not do the same, other issues will consume the bandwidth of the public and the politicians, and science policy will get crowded out.

These efforts have a track record of success. Our government advocacy efforts have included campaigns that involved large numbers of scientists using their voice to advocate on behalf of numerous science policy issues. These campaigns have brought thousands of letters to our elected officials on behalf of their constituents and advised them on issues such as ensuring a steady supply of critical minerals, the America COMPETES Act, the Manufacturing Initiative, and the strategic helium reserve. Following these outreach efforts, many of these initiatives were signed into law. While no single organization may claim sole credit for these successes, a combined chorus of voices has made these advances possible.

Many of my colleagues have infused their scientific knowledge directly into policymaking. They serve in Congress and the White House, across various government agencies, and in think tanks around the country. They dedicate their careers to science policy advancement, and their scientific training and knowledge of the complex range of issues is extremely valuable. We are currently underrepresented on Capitol Hill; only two Congresspersons have PhDs in science. If we encourage public service as a viable career option among scientists and engineers, our voice will become much stronger.

My graduate research experience included a visit to a country without a democratic system as robust as the one in the United States. Upon learning about my advocacy efforts, my colleagues over there expressed skepticism about my ability to influence real policy. I am not naïve; these efforts will take time, and change will not occur overnight. However, much like our research, we must tirelessly embrace this endeavor, and, step by step, make progress. As scientists, we stand beyond partisan rhetoric and are recognized as reputable experts in our research fields. This unique position empowers us with a very influential voice, and we must effectively and responsibly wield it.

Boris Dyatkin is a volunteer writer for MRS Bulletin. The views expressed in the article are his own. 